\title{
The relationship between psychological distress with salivary $\alpha$-amylase and stress related symptoms among breast cancer survivors
}

\author{
H. W. Yong ${ }^{1}$, H. Zailina ${ }^{1 *}$, J. O. Zubaidah ${ }^{2}$, M. Saidi ${ }^{3}$, H. Y. Yong ${ }^{4}$, M. S. Zalilah ${ }^{4}$ \\ ${ }^{1}$ Department of Environmental and Occupational, Faculty of Medicine and Health Sciences, Universiti Putra Malaysia, Selangor, \\ Malaysia; ${ }^{*}$ Corresponding Author: zailina@medic.upm.edu.my \\ ${ }^{2}$ Department of Psychiatry, Faculty of Medicine and Health Sciences, Universiti Putra Malaysia, Selangor, Malaysia \\ ${ }^{3}$ Department of Biomedical Sciences, Faculty of Medicine and Health Sciences, Universiti Putra Malaysia, Selangor, Malaysia \\ ${ }^{4}$ Department of Nutrition and Dietetics, Faculty of Medicine and Health Sciences, Universiti Putra Malaysia, Selangor, Malaysia
}

Received 20 February 2013; revised 27 March 2013; accepted 11 April 2013

Copyright (C) 2013 H. W. Yong, et al. This is an open access article distributed under the Creative Commons Attribution License, which permits unrestricted use, distribution, and reproduction in any medium, provided the original work is properly cited.

\section{ABSTRACT}

Background and Aims: This study examined the stress levels, the stressors and biomarker such as Alpha ( $\alpha$ )-Amylase enzyme which is secreted under distress conditions. The aim was to determine the relationship between these three variables. Methods: The study respondents were made up of cancer outpatients from 3 hospitals namely the Hospital Kuala Lumpur, Seberang Jaya and Johor Baru, Pantai Ipoh and Putrajaya. The Personal Stress Inventory (PSI) questionnaire was used to identify stressors, while the Hospital Anxiety and Depression Scale (HADS) were used to determine the psychological distress levels. The Salimentary Oral Swab (SOS) Technique was used to collect the saliva and then the Salivary $\alpha$-Amylase Assay Kit was used to analyse for $\alpha$ amylase. Results: The majority of respondents were stressed due to their sensitive emotion and nervousness in their daily lives (68.7\%), they had poor memory and short attention spans of carrying out job tasks (67.3\%) as well as they were emotionally depressed (65.3\%). Their poor memory and short attention span $(p=0.037)$, heavy work load and poor task delivery $(p=0.008)$ were predictors for distress using HADS. The salivary $\alpha$-amylase concentration was significantly related to the stress levels $(p=0.002)$. Conclusion: Breast cancer respondents with musculoskeletal system related symptoms, with heavy work load and poor task delivery, as well as had poor memory and short attention span were at higher risk of experiencing psychological distress. The salivary $\alpha$-amylase which had significant relationships with psychological distress was therefore, a potential biological indicator for distress, while the musculoskeletal system related symptoms from the PSI questionnaire were predictors for distress.

Keywords: Breast Cancer Survivors; Salivary $\alpha$-Amylase; Stress-Related Symptoms; Distress

\section{INTRODUCTION}

Stress can be expressed in various ways and the common stress-related symptoms are musculoskeletal system such as back pain, general aches and pains; poor memory and attention span such as lack of focus, forgetfulness; gastrointestinal system such as eating too much or not eating, upset stomach; lack of physical energy, tension due to emotion such as short temper and sleeping disturbance which can lead to more severe psychological outcome [1].

Psychological distress is the most frequent and common psychological outcome studied. Most of the measurements were mainly based on self-reported questionnaire instead of biological measurement [2]. Saliva had been widely used due to its cost-effective approach for screening of large populations and can be used as an indicator of distress, however, most studies were on cortisol levels [3].

Recently, due to its noninvasiveness and easy availability, the use of $\alpha$-amylase as the indirect measure of SNS had gained rapid attention [4-6]. To date very few researches had examined the relationship between salivary $\alpha$-amylase level and psychological distress. 
Both human and animal studies had proposed that elevation of salivary enzyme $\alpha$-amylase reflects autonomic activation [4]. When an individual is stressed, the stress hormones are secreted. Two bodily systems such as the autonomic nervous system (ANS) and hypothalamic pituitary adrenal system (HPA axis) would be activated. Among these two bodily systems, autonomic nervous systems (ANS) were normally neglected by researchers. ANS which comprised the sympathetic nervous system (SNS) and parasympathetic nervous system (PNS) prepares the body during stressed situations [6,7]. There are two common measures available for ANS, the catecholamines epinephrine (EPI) and norepinepherine (NE) but findings proved direct measure of salivary EPI or NE did not reflect the SNS reactions. The use of $\alpha$-amylase as the indirect measure of SNS had gained rapid attention.

Fortunately, a noninvasive way of measuring SNS is by sampling the surrogate of SNS activity such as the salivary $\alpha$-amylase level $[7,8]$. Other studies had proven the increased secretion of salivary $\alpha$-amylase level under distress conditions [9-11]. Beside these, strong positive association was also found between salivary $\alpha$-amylase and stress response as well as its influence on individual internal (i.e. distress) and external problems (i.e. aggression) $[6,11]$.

\section{MATERIALS AND METHOD}

The Personal Stress Inventory (PSI), Hospital Anxiety and Depression Scale (HADS) questionnaires were translated to the Malay and Chinese language. Results carried out on the reliability as well as validity tests were acceptable.

\subsection{Biological Sampling}

The salivary samples were collected according to the Salimentary Oral Swab (SOS) instruction for use (Part No. 5001.02) (Salimetrics). Oral swab was placed into mouth between upper cheek and gum for 1 - 2 minutes, after which the oral swab was inserted into the storage tube and sealed with cap. For analysis, all samples were centrifuged at $3000 \mathrm{rpm}$ for 15 minutes. The saliva $\alpha$ amylase was analyzed using the Salimetrics salivary $\alpha$-amylase assay kit.

\subsection{Personal Stress Inventory (PSI)}

PSI was developed to assess the physiological symptoms of stress and at the same time measures the personal stressor that induces stress to respondents. It is divided into 2 parts. Part 1 consists of 12 items on the perception of personal stressors. The personal stressors scoring is the same as Part 1 and can be further divide into 4 subscales which include family and household factors (11 items), environmental factors ( 7 items), diseases ( 9 items) and other factors in the life events during the past 1 month. Raw scores are calculated by summing the items scores of each subscale. The total score of 36 and above will be considered as stress. Part 2 measures the stress based on the reported symptoms. This part includes 52 items which measures the symptoms of stress. The symptom of stress was rated on a Likert-scale with 4 responses from 0 to 3 [12].

Stress-related symptoms were a part of the PSI questionnaire which include 53 items that divide into 11 subscales such as musculoskeletal systems related symptoms (4 items), gastrointestinal systems related symptoms (6 items), physical systems related symptoms (6 items), depression related emotion (6 items), tension due to emotion and nervousness (11 items), physical energy problem (3 items), sleeping habit and pattern problem (3 items), memory and attention span problem (5 items), dietary pattern (3 items), work load and task delivery problem (3 items), personal and sexual relationship problem (3 items). Each subscale item was rated on a Likert-scale ranging from 0 to 3 . A score of 0 indicates no symptom while 3 for symptoms occurrence of almost every day. A score of $\geq 1$ indicates the presence of the subscales related symptoms [12].

\subsection{Hospital Anxiety and Depression Scale (HADS)}

HADS is first developed to screen the depression and anxiety among the hospitalized ill population. HADS consists of 14-item which can be divided into two subscales, 7 items subscales measuring anxiety and another 7 item subscales measuring depression. Therefore, it is used to determine the psychological distress levels of respondents [13]. Each of items will be scored on a 4 point Likert scale of $0-3$, giving both anxiety and depression a maximum score of 21 respectively, with a maximum score of 42 for total. A total score of $\geq 15$ indicates the presence of psychological distress [14-16].

\section{RESULTS}

\subsection{Socio-Demographic and Medical History of Respondents}

Table 1 shows the information on the background and medical history of the respondents. The mean age was 49.11 (SD 7.10) years and the duration of employment was 19.34 years (SD 10.32). Most respondents were Malay (50.7\%), married (76.0\%), with secondary level of formal education $(52.0 \%)$. More than half of the respondents $(57.3 \%)$ were diagnosed with Stage II and $56.7 \%$ did not have a family history of breast cancer. 
Table 1. Socio-demographic and medical history of respondents.

\begin{tabular}{ll}
\hline Variables & No. of subjects (\%) \\
\hline Age $(\mathrm{M} \pm \mathrm{SD})$ & $49.1 \pm 7.1$ \\
Duration of employment $(\mathrm{M} \pm \mathrm{SD})$ & $19.3 \pm 10.3$ \\
Ethnicity & \\
$\quad$ Malay & $76(50.7)$ \\
$\quad$ Chinese & $67(44.7)$ \\
$\quad$ Indian & $7(4.6)$ \\
Marital status & $114(76.0)$ \\
$\quad$ Married & $36(24.0)$ \\
$\quad$ Single & \\
Educational level & $6(4.0)$ \\
$\quad$ No formal education & $29(19.3)$ \\
$\quad$ Primary education & $78(52.0)$ \\
$\quad$ Secondary education & $37(24.7)$ \\
Tertiary education & \\
Stages of cancer & $64(42.7)$ \\
$\quad$ Stage I & $86(57.3)$ \\
Stage II & \\
Family history of breast cancer & $65(43.3)$ \\
$\quad$ Yes & $85(56.7)$ \\
$\quad$ No & \\
N =150 & \\
\hline
\end{tabular}

\subsection{Distribution of $\alpha$-Amylase Level (U/ml) among Breast Cancer Survivors}

Salivary $\alpha$-amylase levels (U/ml) of breast cancer survivors showed the mean of salivary $\alpha$-amylase level was 164.11 U/ml with a standard deviation of $166.13 \mathrm{U} / \mathrm{ml}$ ranging from 0.3 to $704.9 \mathrm{U} / \mathrm{ml}$. The distribution of Salivary $\alpha$-amylase was not normal as it is more skewed to the right (positively skewed).

\subsection{Stress-Related Symptoms}

Table 2 shows the most reported stress-related symptoms of the respondents obtained from the PSI questionnaire. Among all the stress-related symptoms, majority reported being tense due to emotionally sensitive and nervousness $(68.7 \%)$ as well as had poor memory and short attention span $(67.3 \%)$. These were followed by emotional depression $(65.3 \%)$, physical system related symptoms $(56.7 \%)$, heavy work load and poor task delivery $(53.3 \%)$ and gastrointestinal system related symptoms $(48.7 \%)$. Personal and sexual relationship problem was the least reported symptom, with only $37.3 \%$.

\subsection{Relationship between Salivary $\alpha$-Amylase and Stress-Related Symptoms (PSI) with Psychological Distress Using HADS}

Table 3 shows that the salivary $\alpha$-amylase, poor memory and short attention span, at the same time had heavy work load with poor task delivery were predictors for distress among respondents using HADS. Those with an increase in $1 \mathrm{U} / \mathrm{ml}$ of salivary $\alpha$-amylase had 6.48 times
Table 2. Distribution of stress-related symptoms among survivors.

\begin{tabular}{lc}
\hline Variables & $\mathbf{N}(\%)$ \\
\hline Musculoskeletal related symptoms & $69(46.0)$ \\
Gastrointestinal related symptoms & $73(48.7)$ \\
Physical related symptoms & $85(56.7)$ \\
Emotional depression & $98(65.3)$ \\
Emotional and nervous tension & $103(68.7)$ \\
Lack of energy & $87(58.0)$ \\
Sleeping problem & $80(53.3)$ \\
Poor memory and short attention span & $101(67.3)$ \\
Poor dietary pattern & $48(32.0)$ \\
Heavy work load and poor task delivery & $80(53.3)$ \\
Personal and sexual relationship problem & $56(37.3)$ \\
$\mathrm{N}=150$ & \\
\hline
\end{tabular}

the odds to be distressed $(p=0.002)$. Survivors with poor memory and short attention span were 5.42 times the odds to be distressed $(\mathrm{p}=0.037)$ and those with heavy work load and poor task delivery had 4.38 time the odds to be distressed $(\mathrm{p}=0.008)$. These results reflected a good overall fitness of the model when Hosmer-Lemeshow test $(\mathrm{p}>0.05)$ and the area under the ROC curve (AUC) were at least $70 \%$ in the accuracy discrimination of the cases.

\section{DISCUSSION}

Salivary collection is a more convenient method than the blood collection since it is noninvasive, therefore, multiple samples can be studied simultaneously in the laboratory $[4,6,17,18]$ as well as prevented the stressinducing effects of blood sampling [19]. Since last decade, the effects of cortisol as a stress indicator had been widely investigated, while, salivary $\alpha$-amylase as a stress indicator received attention only over the past few years [7]. In major cases, the salivary $\alpha$-amylase increase in response to psychological stress, may be higher than the salivary cortisol and in previous psychological research, findings showed that $\alpha$-amylase measurement as a potential indicator of distress $[6,9]$. Thus, this study investigated the relationship between distress level using Salivary $\alpha$-amylase of the breast cancer survivors.

Unsystematic saliva collection techniques in the mouth may result in variations of the salivary $\alpha$-amylase levels. Research showed salivary $\alpha$-amylase levels depend on location of its collection in the mouth. Thus, the oral swab technique, which is a common method, was used in this study to ensure the validity. The oral swab was placed at the cheek opposite the 2nd upper molar, where the salivary $\alpha$-amylase concentration was saturated [19].

The distribution of salivary $\alpha$-amylase scores was 
Table 3. Salivary $\alpha$-amylase and stress-related symptoms as predictor of distress using HADS scale.

\begin{tabular}{|c|c|c|c|c|c|c|}
\hline \multirow[b]{2}{*}{ Variables } & \multicolumn{3}{|c|}{ Simple Logistic Regression } & \multicolumn{3}{|c|}{ Multiple Logistic Regression } \\
\hline & $\mathrm{b}$ & Crude OR $(95 \% \mathrm{CI})$ & $\mathrm{p}$ & $\mathrm{b}$ & $\begin{array}{c}\text { Adjusted OR } \\
(95 \% \mathrm{CI})\end{array}$ & $\mathrm{p}$ \\
\hline Salivary $\alpha$-amylase & 1.91 & $6.73(2.35,19.26)$ & $<0.001^{* * *}$ & 1.87 & $6.48(1.95,21.52)$ & $0.002^{* *}$ \\
\hline Musculoskeletal related symptoms & 1.45 & $4.27(1.82,10.00)$ & $0.001^{* *}$ & - & - & - \\
\hline Gastrointestinal related symptoms & 0.78 & $2.19(0.99,4.86)$ & 0.054 & - & - & - \\
\hline Physical symptoms & 1.09 & $2.97(1.24,7.12)$ & $0.015^{*}$ & - & - & - \\
\hline Emotional depression & 1.62 & $5.04(1.67,15.28)$ & $0.004^{* *}$ & - & - & - \\
\hline Emotional and nervous tension & 1.80 & $6.03(1.74,20.92)$ & $0.005^{* *}$ & - & - & - \\
\hline Lack of energy & 1.23 & $3.41(1.37,8.47)$ & $0.008^{* *}$ & - & - & - \\
\hline Sleeping problem & 1.69 & $5.43(2.09,14.14)$ & $0.001^{* *}$ & - & - & - \\
\hline Poor memory and short attention span & 2.34 & $10.41(2.38,45.58)$ & $0.002^{* *}$ & 1.69 & $5.42(1.16,26.44)$ & $0.037^{*}$ \\
\hline Poor dietary pattern & 0.92 & $2.50(1.13,5.53)$ & $0.024^{*}$ & - & - & - \\
\hline Heavy work load with poor task delivery & 1.95 & $7.00(2.53,19.39)$ & $<0.001^{* * *}$ & 1.48 & $4.38(1.46,13.14)$ & $0.008^{* *}$ \\
\hline Personal and sexual relationship problem & 1.08 & $2.93(1.33,6.48)$ & $0.008^{* *}$ & - & - & - \\
\hline
\end{tabular}

"Significant at $\mathrm{p}<0.05 ;{ }^{* *}$ Significant at $\mathrm{p}<0.01 ;{ }^{* * *}$ Significant at $\mathrm{p}<0.001 ; \mathrm{N}=150 ;$ Hosmer-Lemeshow test, $(\mathrm{p}=0.913)$, and the area under the ROC curve $(82.6 \%)$ were applied to check the model fitness.

positively skewed (skewed to the right) and log transformations was used to normalize the distributions. It is a normal finding for saliva collected on the absorbent of oral swabs [20]. Similar to Granger et al. [6] results where the distribution of salivary $\alpha$-amylase scores were skewed to the right. Findings showed that tension due to emotion and nervousness was the most reported symptom among breast cancer survivors. A local study using PSI to investigate the stress-related symptoms also indicated the most common symptoms experienced were tension due to emotion and nervousness [21] which was similar with this study, where it was also the most common stress-related symptoms reported (68.7\%), followed by poor memory and short attention span (67.3\%), emotional depression $(65.3 \%)$ and lack of physical energy $(58.0 \%)$. Other research findings also had indicated tension-related symptoms such as fear of future, uncertainty and worry were commonly reported by survivors $[22,23]$.

No significant correlation found between salivary $\alpha$ amylase and socio-demographic indicating that Salivary $\alpha$-amylase is independent of possible confounders and these were in line with Granger et al. [6] and Nater et al. [24]. These researchers also found that salivary enzyme $\alpha$-amylase level was not influenced by socio-demographic confounders such as gender, smoking, and other activity levels but significantly influenced by social behaviors, negative psychological outcomes, and cardiovascular problems $[6,24,25]$.

Salivary $\alpha$-amylase is an enzyme produced in the oral cavity by salivary gland (human parotid gland) and had been identified as surrogate markers for ANS activity in which its secretion is in response to neurotransmitter stimulation [26]. Hypothalamus axis and norepinephrine system are activated during stress and autonomic nervous system (ANS) will be executed. The ANS response will increase the respiratory, gastrointestinal, cardiovascular activities and cause endocrine changes in response to stress. Secretion of salivary $\alpha$-amylase is under the control of ANS. Thus, assumption can be made that salivary $\alpha$-amylase level increased when an individual is under psychological distress. Interestingly, several evidences showed significant relationship between salivary $\alpha$-amylase with psychological outcomes [10,25,27-29]. These findings were similar to this study, where salivary $\alpha$ amylase level showed significant association and was a predictor for distress $(p=0.002)$ on HADS.

Stress-related symptoms were the end-results of our bodies' response to stress and prolonged stress can induce negative psychological outcomes (i.e. distress). These responses normally involve hormonal secretion such as $\alpha$-amylase which was significantly correlated with psychological distress. Findings showed that Salivary $\alpha$-amylase was significantly related to the distress levels using the HADS scale.

Stress-related symptoms had significant association with distress $(\mathrm{p}<0.05)$ and musculoskeletal symptoms, poor memory and short attention span or heavy work load and poor task delivery were significant predictors for distress $(\mathrm{p}<0.05)$. This is in line with Rohleder et al. [30], where abnormal stress could not only evolve psychological distress, but is also able to affect organ systems such as the musculoskeletal systems.

\section{CONCLUSION}

Findings showed salivary $\alpha$-amylase levels had significant relationship with psychological distress of sur- 
vivors and is therefore, also a potential biological indicator for Asian population, while the stress-related symptoms from the PSI scale were predictors for psychological distress. Therefore, breast cancer survivors with musculoskeletal symptoms, had heavy work load and poor task delivery as well as had poor memory and short attention span were at highest risk to be psychologically distressed.

\section{ACKNOWLEDGEMENTS}

We would like to thank MAKNA for the research grant and collaboration. Ipoh Ampang Puteri, Seberang Jaya, Johore Bahru, Segamat and Kuala Lumpur General Hospital, cancer outpatients who participated in the study as well as the hospital management for their cooperation.

\section{REFERENCES}

[1] US Department of Health and Human Services (2010) Stress and your health fact sheet. http://www.womenshealth.gov

[2] Uchida, M., Akechi, T., Okuyama, T., Sagawa, R., Nakaguchi, T., Endo, C., Yamashita, H., Toyama, T. and Furukawa, T.A. (2010) Patients' supportive care needs and psychological distress in advanced breast cancer patients in Japan. Japanese Journal of Clinical Oncology, 41, 530-536.

[3] Kaufman, E. and Lamster, I.B. (2002) The diagnostic applications of saliva: A review. Critical Reviews in Oral Biology and Medicine, 13, 197-212. doi:10.1177/154411130201300209

[4] Nater, U.M., Rohleder, N., Gaab, J., Berger, S., Jud, A., Kirschbaum, C. and Ehlert, U. (2005) Human salivary $\alpha$ amylase reactivity in a psychosocial stress paradigm. International Journal of Psychophysiology, 55, 333-342. doi:10.1016/j.ijpsycho.2004.09.009

[5] van Stegeren, A., Rohleder, N. and Everaerd, W. (2006) Salivary alpha-amylase as marker for adregenic activity during stress: Effect of betablockade. Psychoneuroendocrinology, 31, 137-141. doi:10.1016/j.psyneuen.2005.05.012

[6] Granger, D.A., Kivlighan, K.T., El-Sheikh, M., Bordis, E.B. and Stroud, L.R. (2007) Salivary $\alpha$-amylase in biobehavioral research. Recent developments and applications. Annals of New York Academy of Sciences, 1098, 122-144. doi:10.1196/annals.1384.008

[7] Ruttle, P.P. (2008) Stress and the role of alpha-amylase. http://www.lepanoptique.com/sections/sciences/stress-an d-the-role-of-alpha-amylase

[8] Rohleder, N., Nater, U.M., Wolf, J.M., Ehlert, U. and Kirschbaum, C. (2004) Psychosocial stress-induced activation of salivary alpha-amylase. An indicator of sympathetic activity? Annals of New York Academy of Sciences, 1032, 258-263. doi:10.1196/annals.1314.033

[9] Nater, U.M., La Marca, R., Florin, L., Moses, A., Langhans, W., Koller, M.M. and Ehlert, U. (2006) Stress-induced changes in human salivary alpha-amylase activityassociations with adrenergic activity. Psychoneuroendo- crinology, 31, 49-58.

doi:10.1016/j.psyneuen.2005.05.010

[10] Takai, N., Yamaguchi, M., Aragaki, T., Eto, K., Uchihashi, K. and Nishikawa, Y. (2004) Effect of psychological stress on the salivary cortisol and amylase levels in healthy young adults. Archives of Oral Biology, 49, 963-968. doi:10.1016/j.archoralbio.2004.06.007

[11] Chatterton Jr., R.T., Vogelsong, K.M., Lu, Y.C. and Hudgens, G.A. (1997) Hormonal responses to psychological stress in men preparing for skydiving. Journal of Clinical Physiology, 16, 433-448. doi:10.1111/j.1475-097X.1996.tb00731.x

[12] O’Donnell, M.P., Jaffe, D.T. and Zindler Wernet P. (1984) Stress assessment. In: O'Donnell, M.P. and Ainsworth, T.H., Eds., Health Promotion in the Work Place, John Wiley, New York, 185-220.

[13] Terluin, B., Brouwers, E.P.M., van Marwijk, H.W.J., Verhaak, P.F.M. and van der Horst, H.E. (2009) Detecting depressive and anxiety disorders in distressed patients in primary care; comparative diagnostic accuracy of the Four-Dimensional Symptom Questionnaire (4DSQ) and the Hospital Anxiety and Depression Scale (HADS). BMC Family Practice, 10, 58. doi:10.1186/1471-2296-10-58

[14] Cohen, M., Hoffman, R.G., Cromwell, C., Schmeidler, J., Ebrahim, F., Carrera, G., Endorf, F., Alfonso, C.A. and Jacobson, J.M. (2002) The prevalence of distress in persons with human immunodeficiency virus infection. Psychosomatics, 43, 10-15. doi:10.1176/appi.psy.43.1.10

[15] Shim, E.J., Shin, Y.W., Jeon, H.J. and Hahm, B.J. (2008) Distress and its correlates in Korean cancer patients: Pilot use of the distress thermometer and the problem list. Psycho-Oncology, 17, 548-555. doi:10.1002/pon.1275

[16] NCCN (2002) Practice guidelines in oncology - v. distress management. National Comprehensive Cancer Network.

[17] Hoffman, B. (2005) Cancer survivors at work: A generation of progress. A Cancer Journal for Clinicians, 55, 271-280. doi:10.3322/canjclin.55.5.271

[18] Paige, S.Z. and Streckfus, C.F. (2007) Salivary analysis in the diagnosis and treatment of breast cancer. General Dentistry, 55, 156-157.

[19] Harmon, A.G., Towe-Goodman, N.R., Fortunato, C.K. and Granger, D.A. (2008) Differences in saliva collection location and disparities in baseline and diurnal rhythms of alpha-amylase: A prelimary note of caution. Hormones and Behavior, 54, 592-596. doi:10.1016/j.yhbeh.2008.05.019

[20] Yamaguchi, M., Wakasugi, J. and Sakakima, J. (2008) Competitive and product inhibition-based alpha-amylase activity analysis method. Clinical Biochemistry, 41, 325330. doi:10.1016/j.clinbiochem.2007.10.016

[21] Shamsul, I.A.A. and Hassim, N.J. (2005) The prevalence of occupational stress among general practitioner in Ampang, Selangor. Malaysian Journal of Community Health, 11, 44-50.

[22] Schou, I., Ekeberc, Q. and Sandvick, L. (2005) Multiple predictors of health-related quality of life in early stage breast cancer. Data from a year follow-up study compared 
with the general population. Quality of Life Research, 14, 1813-1823. doi:10.1007/s11136-005-4344-Z

[23] Thewes, B., Butow, P., Girgis, A. and Pendlebury, S. (2004) The psychosocial needs of breast cancer survivors; A qualitative study of the shared and unique needs of younger versus older survivors. Psycho-Oncology, 13, 177189. doi:10.1002/pon. 710

[24] Nater, U.M., Rohleder, N., Schlotz, W., Ehlert, U. and Kirschbaum, C. (2007) Determinants of the diurnal course of salivary alpha-amylase. Psychoneuroendocrinology, 32, 392-401. doi:10.1016/j.psyneuen.2007.02.007

[25] Inagaki, T., Miyaoka, T., Okazaki, S., Yasuda, H., Tetsuya, K., Utani, E., Wake, R., Hayashida, M., Horiguchi, J. and Tsuji, S. (2010) High salivary alpha amylase levels in patients with schizophrenia: A pilot study. Neuro-Psychopharmacology and Biological Psychiatry, 34.

[26] Garrett, J.R. (1999) Effects of autonomic nerve stimulations on salivary parenchyma and protein secretion. In: Garrett, J.R., Ekstrom, J. and Anderson, L.C., Eds., Neural Mechanisms of Salivary Gland Secretion, Karger, Basel, 59-79.
[27] Chatterton, R.T.J., Vogelsong, K.M., Lu, Y.C., Ellman, A.B. and Hudgens, G.A. (1996) Salivary alpha-amylase as a measure of endogenous adregenic activity. Clinical Physiology, 16, 433-448. doi:10.1111/j.1475-097X.1996.tb00731.x

[28] Noto, Y., Sato, T., Kudo, M., Kurata, K. and Hirota, K. (2005) The relationship between salivary biomarkers and state-anxiety anxiety inventory score under mental arithmetric stress: A pilot study. Anesthesia and Analgesia, 101, 1873-1876. doi:10.1213/01.ANE.0000184196.60838.8D

[29] Bosch, J.A., Brand, H.S., Ligtenberg, T.J.M., Bermond, B., Hoogstraten, J. and Nieuw Amerongen, A.V. (1996) Psychological stress as a determinant of protein levels and salivary-induced aggregation of Streptococcus gordonii in human whole saliva. Psychosomatic Medicine, 58, 374-382.

[30] Rohleder, N., Chen, E., Wolf, J.M. and Miller, G.E. (2008) The psychobiology of trait shame in young women: Extending the social self preservation theory. Health Psychology, 27, 523-532. doi:10.1037/0278-6133.27.5.523 